\title{
Behaviour of the Australian 'fire-beetle' Merimna atrata (Coleoptera: Buprestidae) on burnt areas after bushfires
}

\author{
Anke Schmitz', Erik S. Schneider ${ }^{2}$ and Helmut Schmitz ${ }^{1, *}$ \\ 1 Institute for Zoology, University of Bonn, Poppelsdorfer Schloss, 53115 Bonn, Germany. \\ ${ }^{2}$ Institute for Zoology, Karl-Franzens-University Graz, Universitätsplatz 2, 8010 Graz, Austria. \\ *Corresponding author: h.schmitz@uni-bonn.de
}

\begin{abstract}
The Australian 'fire-beetle' Merimna atrata can be found in large numbers directly after a fire in eucalyptus forests in the smoky burnt area. The main reasons for this so-called pyrophilous behaviour are reproduction and foraging. Beetles of both sexes are most probably attracted by the smell of burning eucalyptus trees and invade a freshly burnt area as early as possible. Nearly the entire cycle of reproduction, including mate finding, copulation and oviposition takes place, and the beetles are most likely protected from predators by heat and smoke. This is possible because $M$. atrata has developed special infrared receptors on the abdomen which serve for the detection of hot spots. As the burnt area gets cooler and the smell of burning declines, beetles disappear within about 3 days. Observations on burnt areas over a period of 12 years also have revealed that $M$. atrata is a diurnal sunloving beetle which prefers high body temperatures above $40^{\circ} \mathrm{C}$.
\end{abstract}

KEYWORDS: pyrophilous insect, forest fire, fire detection, infrared reception, Western Australia

\section{INTRODUCTION}

The Australian 'fire-beetle' Merimna atrata (Gory \& Laporte, 1837) (Buprestidae) bears its name because this so-called pyrophilous beetle heads for forest fires (Poulton 1915; Schmitz and Schmitz 2002). M. atrata is the only species of the genus Merimna and is distributed all over Australia (Hawkeswood 2007), but has not been found outside the Australian mainland. The first report dealing with the pyrophilous behaviour of $M$. atrata was published more than 120 years ago (Tepper 1887). Tepper noted that under normal conditions this beetle is hard to find and could never be found on flowers (Tepper 1887). Accordingly Poulton (1915) wrote that M. atrata is only seen when a bushfire is raging. In contrast to these older reports, however, Williams and Williams (1983) described the "Dwarf Apple" Angophora hispida as an adult host plant, implying that $M$. atrata visits flowers during the day. During a bushfire, M. atrata adults seem to approach the fire from all directions, flying straight into it (Poulton 1915). Tepper (1887) reported that thousands of beetles were in flight one or two hours after a bushfire in localities where searches for beetles had previously been fruitless. Having arrived on the freshly burnt area beetles become very agile and have been seen running over hot steaming branches and sometimes even over parts that are glowing red but without damage to the tarsi (Poulton 1915). Although not specifically stated in these older reports, it is probable that these observations were made during the day. However, it has also been noted that M. atrata is nocturnal (Moore and Brown 1985). The reason for this assessment may be that $M$. atrata has been reported to be attracted to artificial lights at night (Williams 1982; Hawkeswood 1992).

It has been hypothesised that the beetles were stimulated by the scent of the fire to seek a place where their larvae can feed upon wood from which volatile protective substances have been removed by the heat (Poulton 1915). In general the larvae of M. atrata are most probably associated with fire-damaged eucalyptus trees (Hawkeswood 2007). Until now, however, only fire-killed Eucalyptus (currently genus Corymbia) calophylla (Hawkeswood and Peterson 1982) and burnt stumps of Baeckea frutescens (Myrtaceae) (Kitchin 2009) have been described as potential food plants for the larvae (cf. Table 1).

In contrast to nearly all other members of the otherwise brightly coloured family Buprestidae, adults of M. atrata are uniformly black (Figures 1A, D, E). This can be interpreted as a special adaptation as $M$. atrata is hard to discover when resting on the bark of a burnt tree (Figures 1A, 2B). Another adaptation to 
TABLE 1 Larval food plants of $M$. atrata.

\begin{tabular}{llll} 
Name & Common name & Family & Described by \\
\hline Eucalyptus = Corymbia calophylla & Marri & Myrtaceae & Hawkswood and Petersen 1982 \\
Baeckea frutescens & & Myrtaceae & Kitchin 2009 \\
Eucalyptus gomphocephala & Tuart & Myrtaceae & This paper \\
Eucalyptus marginata & Jarrah & Myrtaceae & This paper \\
Melaleuca rhaphiophylla & Swamp paperbark & Myrtaceae & This paper \\
\hline
\end{tabular}

the pyrophilous lifecycle are its infrared (IR) sensing capabilities. One to three pairs of IR receptor organs occur on the abdomen (Schmitz et al. 2000; Mainz et al. 2004).

What is still missing in the literature is a comprehensive description of the behaviour of $M$. atrata on a freshly burnt area after a fire. Of special interest are the first three days when most of the reproductive cycle of the species occurs. In view of the very special habitat it is postulated that $M$. atrata shows specific adaptations to cope with the threats on a smoky burnt area. In this paper we describe the behaviour of $M$. atrata on burnt areas after wildfires in Western Australia (WA). An attempt is made to provide detailed insight into the biology and ecology of this highly pyrophilous beetle which is perfectly adapted to bushfires and to resolve some of the contradictory information currently existing in the literature.

\section{METHODS}

\section{STUDY SITES}

Observations of the behaviour of $M$. atrata after fires were made in forests in south-western WA located within a radius of roughly $100 \mathrm{~km}$ around the city of Perth. Thus our study sites extended from forests near Gingin and Bindoon in the north to the eastern forests of the Darling Range and extended down to Mandurah and Dwellingup in the south. Beginning in 2002, beetles were observed every year with the exception of 2010 during three-week field trips always lasting from midJanuary to early February. Thus more than 35 freshly burnt areas were inspected, most of them more than once. The sizes of the burnt areas, however, varied considerably from less than one (e.g. a traffic island in Perth) to several thousand hectares in extensive forests outside towns.

\section{OBSERVATIONS OF GENERAL BEHAVIOURAL PATTERNS}

Due to our collaboration with the bushfire brigade of the Western Australian Department of Parks and Wildlife (DPaW, formerly Department of Environment and Conservation) based in Wanneroo, we often arrived at a freshly burnt area while the fire-fighters were still on the ground extinguishing pockets of embers and mopping up. Thus in larger burnt areas many hot spots were still active, mostly also emitting smoke. Even if only small numbers of eucalypt trees were affected by the fire adults of $M$. atrata could be easily observed flying over the burnt area and resting or running around on burnt trees and shrubs.

\section{RECORDING THE NUMBER OF BEETLES ON BURNT TREES}

In January/February 2013 we counted the number of beetles on burnt trees every five minutes for two hours or at fixed times up to four days after a fire. This was done on four different burnt areas (exact locations provided in the captions of Figures 4-7). Because in the mallee woodlands typical of southern WA, eucalyptus trees frequently consist of several trunks arising from the ground (cf. Figures 6, 7), it was not possible to define a simple two-dimensional area of defined size in which beetles could be counted. Therefore we only defined an upper boundary of our observation area at a height of about $2 \mathrm{~m}$. The lower boundary was the field of ash with a radius of about $1 \mathrm{~m}$ around the stem bases. A given tree was observed with a pair of binoculars from a fixed observation point at least five meters away from the tree.

At the first two observation sites we erected a black canvas sheet of $1.5 \times 2 \mathrm{~m}$ as camouflage in front of our observation point. However, it turned out that the erection of the canvas chased away most beetles. On the other hand it was possible to slowly access an observation point without camouflage located next to a larger tree from behind without disturbing the beetles. Thus we omitted the canvas on the following days. All beetles visible within the observation area were counted.

\section{STATISTICS}

Data on the number of beetles counted at different locations and on consecutive days were analyzed using a Friedman test for repeated measures. Level of significance was set at $\mathrm{p}<0.05(* * \hat{=} \mathrm{p}<0.01$; $* \wedge$ ㅇ․ $01 \leq \mathrm{p}<0.05 ;$ n.s. $\triangleq 0.05 \leq \mathrm{p}$ ). 

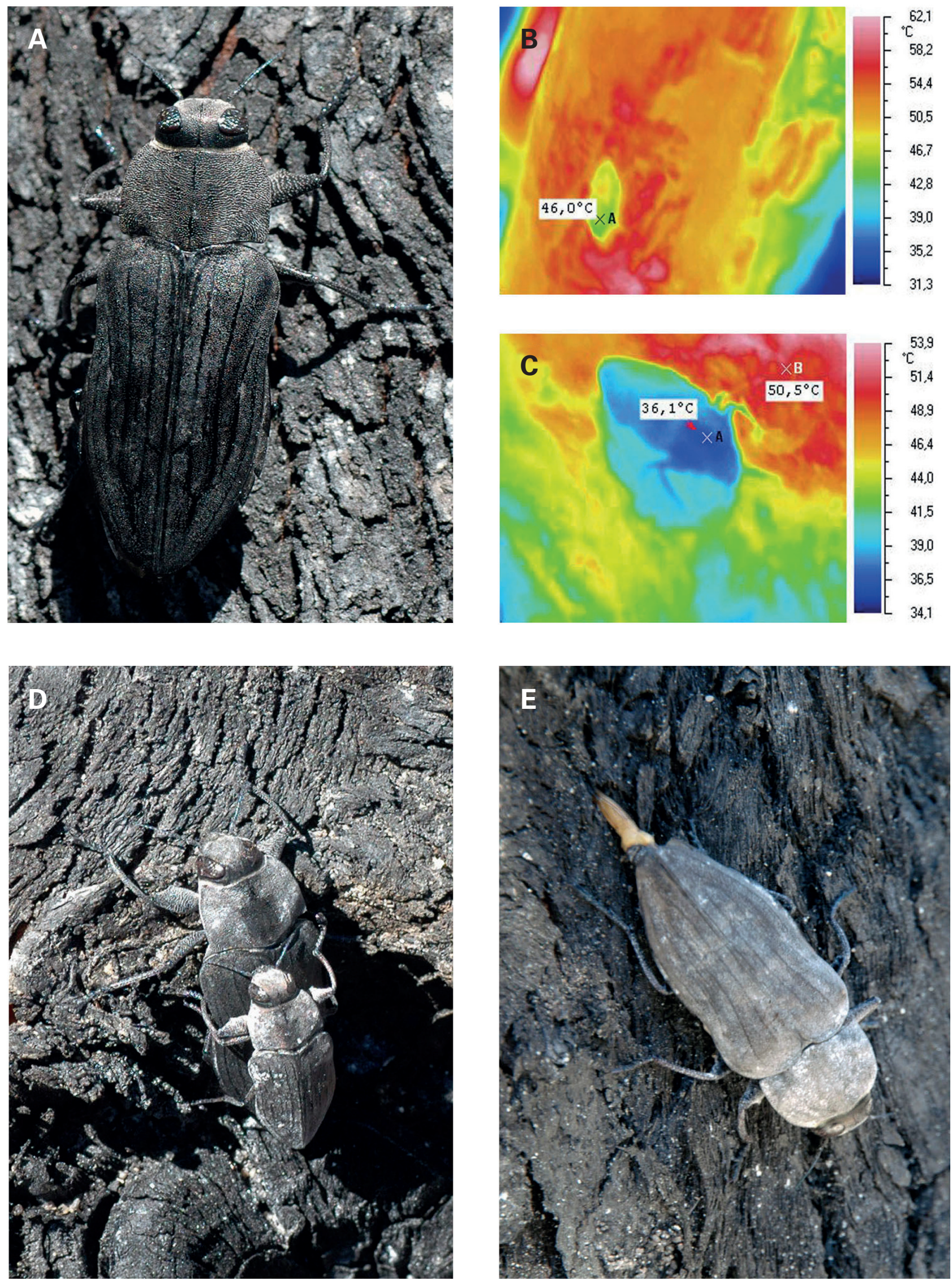

FIGURE 1 A, M. atrata sun basking on burnt bark; B, thermal image of a sun basking beetle; head oriented downwards; thoracic surface temperature $46^{\circ} \mathrm{C} ; \mathrm{C}$, thermal image of a beetle resting at the border between the sunny and shaded region of a burnt stem; thoracic surface temperature $36^{\circ} \mathrm{C}$; $\mathrm{D}$, copulating beetles resting on the sun exposed side of a burnt eucalyptus tree; E, ovipositing female. Body lengths of beetles between 15 and $20 \mathrm{~mm}$. 

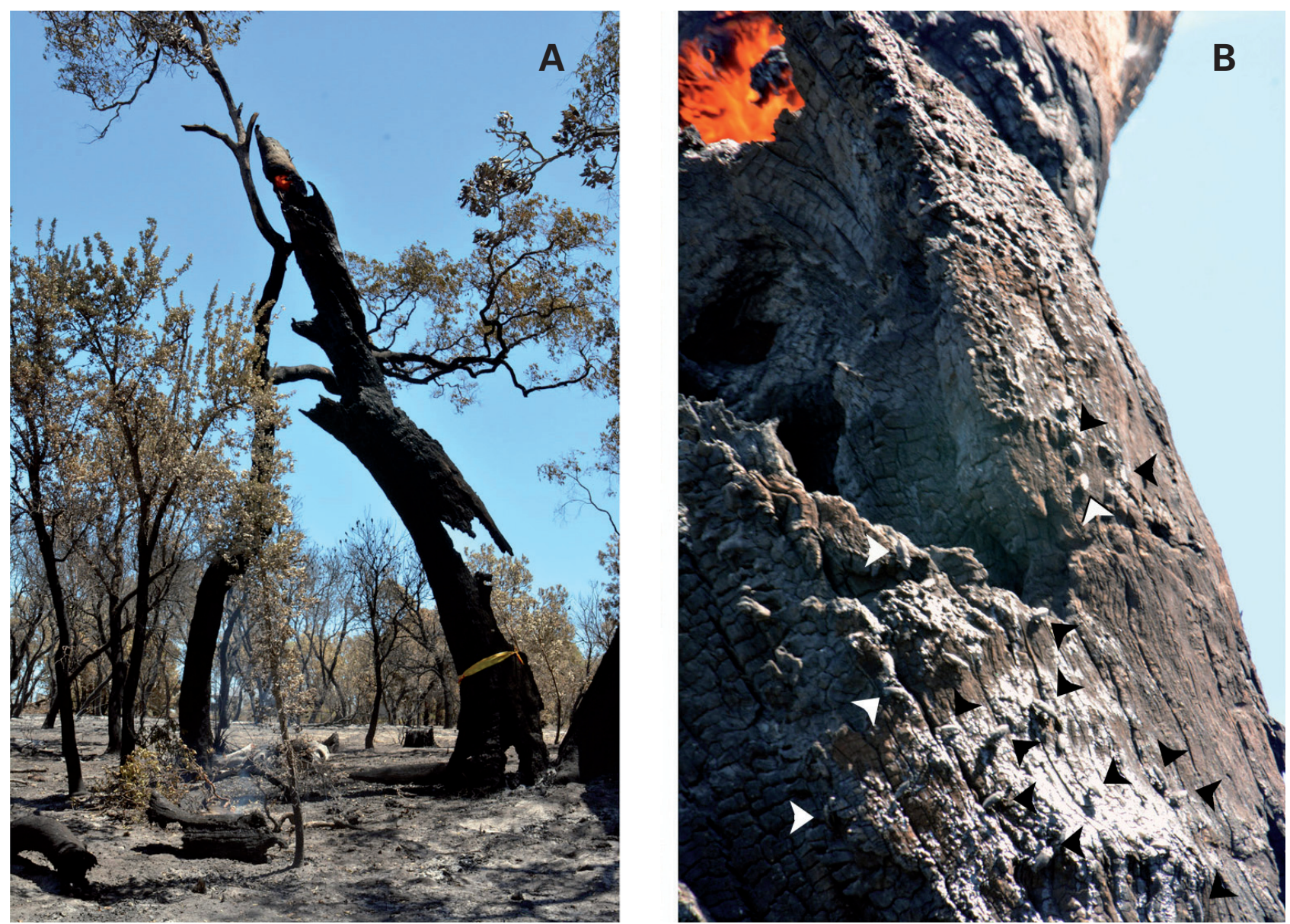

FIGURE 2 A, one day after the fire a tall burnt eucalyptus tree (height about $8 \mathrm{~m}$ ) was still burning and glowing at its top; B, dozens of $M$. atrata (arrowheads) had aggregated directly under the apical glowing zone at a height of about 7 meters.

\section{IR THERMOGRAPHY}

IR thermograms of resting beetles and their surroundings were taken with an IR FlexCam T IR camera (Goratec Inc.). The radiometric camera is equipped with a $160 \times 120$ pixel vanadium oxide focal plane array and a $20 \mathrm{~mm}$ germanium lens. Thermograms were visualised and analysed with GTS Thermography Studio V. 5.1. software (Goratec Inc.). The accuracy of the camera was checked against a blackbody radiator heated to 100,200 , and $300^{\circ} \mathrm{C}$ (CS 500, DIAS Infrared, Dresden, Germany). Deviations from respective temperatures set at the blackbody radiator were always smaller than $1^{\circ} \mathrm{K}$.

\section{RESULTS}

\section{BEHAVIOUR ON FRESHLY BURNT AREAS}

Driven by the prevailing wind the flame front of a forest fire leaves a smoky burnt area. At this early time after the fire, the burnt area is characterised by many hot spots consisting of burning or glowing wood (e.g. fallen trees or broken off branches) and fields of hot ashes. Thus smoke and - especially near larger hot spots - radiant heat is typical for the burnt areas in the first hours after the fire. Initially beetles arrive at the border of the freshly burnt area where they can be observed resting or running around on the vegetation. However, at the earliest time when a human is able to enter the burnt area the beetles also start to invade the scorched terrain.

Adults of M. atrata rapidly spread over the burnt area and can be easily observed flying around relatively close to the ground or running over the ground, trees and shrubs. However, if a beetle rests motionless on burnt bark it is difficult to observe as both sexes are coloured black (Figures 1A, D, E, 2B). Males primarily search for females and often show a stereotypical behaviour: at a height of roughly 1 to $3 \mathrm{~m}$ a male beetle lands on the bark of a burnt eucalyptus tree, immediately turns around and quickly runs down the stem in intermittent running sequences. On their way down to the ground male beetles look for two things: females and food. The beetles often carefully inspect crevices and holes in the bark in search for edible material. As will be described in more detail below, M. atrata is omnivorous. 
Therefore, beetles try to exploit all vegetable and animal food sources (e.g. scorched arthropods). As soon as a male $M$. atrata becomes aware of a female beetle, it vigorously tries to copulate. It jumps onto the back of the other beetle, eventually turns around and tries to insert its aedeagus into the genital chamber of the female (Figure 1D). Often the other beetle also is a male which lugs around the upper male for some time until it tries to shake it off, using its hind legs to kick the upper male away. While doing so the lower male usually bends its abdomen away from the stem up to an angle of $45^{\circ}$ to prevent the upper male from adhering to the bark. The violent kicks eventually causes the upper male to loses its footing; it then falls off and flies away. The rapid reflex to ride another beetle is apparently triggered by the sight of another beetle-like object especially when it is moving. This behaviour was observed on a burnt area south of Perth near Anketell Road in 2002, where some clerid beetles (Trogodendron fasciculatum (Schriebers, 1802)) were also present. All male M. atrata which came close to the dissimilar species immediately tried to copulate with it.

If a female is encountered, a male copulates within a few seconds. However, if the female is already mating it tries to remove the males in the same manner as males do if bothered by another male. The copula lasts for a longer period (not determined so far) and after copulation the females start to deposit their eggs under the bark of the burnt eucalyptus trees by inserting their ovipositor in small crevices (Figure 1E).

During the many years observing $M$. atrata on burnt areas we have learnt that locations where eggs are deposited are very variable. Generally the eggs are laid in trunks and branches of burnt eucalyptus species (Table 1). We have never observed eggs that were deposited in unburnt parts of a tree (e.g. at the border of the burnt area). Severe damage to the region of the tree where the eggs are deposited seems to be important. In most cases eggs are deposited relatively close to the ground (up to about $2 \mathrm{~m}$ ) where the heat of the ground fire has most probably heavily damaged the cambium layer. In this area, and especially older damage of the bark caused by previous fires, seems to be of interest. At those spots the bark is partially broken open by the ground fire and the edges are usually scarred. The deposition of eggs is preferred around the bulging edges of bark. Another surprising behaviour is that females sometimes completely dive into the ash with the tip of the abdomen first. This behaviour was frequently observed even some meters away from the base of a tree. Females stay hidden in the ash for some minutes until they re-emerge and fly away. These ash-covered females look remarkably white for some time (Figure 3A). Although we never were able to verify oviposition under the ash we are convinced that females deposit their eggs in or near roots smothered in ash.
As mentioned above, there is strong evidence that M. atrata also intensely uses the opportunity to forage on the burnt area. All potentially edible material is investigated and if palatable, eaten. We have frequently fed beetles with fruit, peanuts, resins, cheese and meat, among others, and everything was eaten by the beetles. Occasionally we have observed $M$. atrata to feed on dead conspecifics. Also carcases of small fire-killed vertebrates are devoured (Figure 3B).

\section{THERMOREGULATION}

Like most buprestid beetles, M. atrata is a thermophilic species preferring high body temperatures (Evans et al. 2007). Thus the whole behaviour displayed on the freshly burnt area is strongly influenced by thermoregulatory needs. The highest level of activity occurs during the hottest hours of the day. In the hours around noon beetles fly around in the bright sunshine and prefer to land on the sun-exposed sides of tree trunks. Shaded stems and branches are clearly avoided as landing sites. A striking phenomenon which can
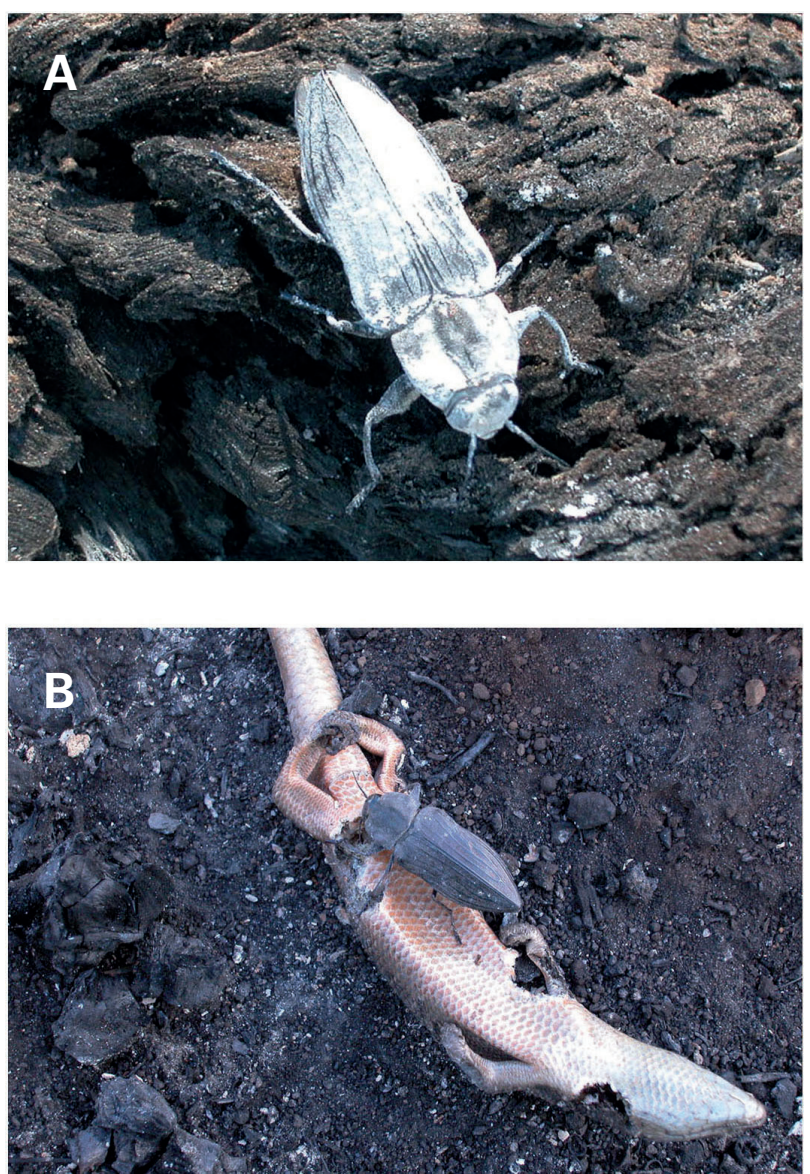

FIGURE 3 A, Female M. atrata powdered with white ash resting on a burnt log after oviposition in the ash; B, M. atrata feeding on a scorched lizard; several pieces had already been bitten out by conspecifics. 
be frequently observed is that the black beetles rest motionless on the jet-black bark of a burnt tree for many minutes in full sunshine (Figure 1A). Because ambient temperatures on hot summer days often already exceed $30^{\circ} \mathrm{C}$, the body temperatures of sun basking beetles can quickly reach temperatures of $40^{\circ} \mathrm{C}$ or more (Figure 1B), suggesting that $M$. atrata is extremely thermophilic. At these high body temperatures beetles are extremely agile and can avoid overheating in different ways by: (i) raising the body away from the bark by extending the legs to maximal lengths under the body thereby facilitating convective cooling along the entire body; (ii) by moving to shaded regions of the stem with characteristic sharp sudden movements (Figure 1C); or (iii) by flying away. Based on our current thermographic measurements on about $30 \mathrm{M}$. atrata, a beetle will not tolerate an increase of its body temperature beyond $46^{\circ} \mathrm{C}$.

\section{PROGRESSION OF BEETLE ACTIVITY AFTER THE FIRE}

In the first hours after a fire, many beetles can be found on the burnt area. As long as the running fire is burning and hot spots on the freshly burnt area emit heat and smoke, further beetles will be attracted. This can be observed at the boundary of smaller burnt areas when beetles fly in from unburnt terrain.

On the first day after the fire, the number of beetles on a given burnt area shows a distinct peak. Even if the firefighters had extinguished all hot spots on smaller burnt areas (cf. Figure 4), beetles stay on the scorched site and display the entire behaviour described above.

Although not so far supported by quantitative investigations it is quite evident that hot spots - even very small ones - increase the numbers of beetles in their immediate vicinity (Figure 2A, B). For example on the third day after a fire, several beetles could still be observed on a broken tree stump with small hot spots at its base (Figure 5). At this spot it was conspicuous that some beetles rested for many minutes at sheltered sites near the base of the trunk.

However, especially when ambient temperatures are high and the tree is sun exposed, the behaviour is very dynamic which is mirrored by the permanently changing numbers of beetles (cf. Figures 4, 5). A continual coming and going can be observed: new beetles arrive eventually chasing away others when landing. Beetles which had run down the stem frequently took off after having crawled a few dozen seconds in the ash on the ground. Another reason that beetles suddenly disappear were attempts by males to copulate with other males. If the lower male finally got rid of the upper one the unsuccessful aggressor frequently flew away.

A continuous decrease in the number of beetles continues over the next days (Figure 6). On the first day at the Gnangara-Moore River State Forest, a smoking hot spot at the base of a tree and another one a few meters away on the broken branch of a fallen tree most probably increased the attractiveness of this spot. On the second day both hot spots were extinguished. However, beetles could still be observed for another two days in significantly declining numbers.

Most probably, hot spots are not the predominant factors defining the general attractiveness of a tree. This is shown in Figure 7 where three neighbouring trees on a small burnt area had been observed. The 2 ha burnt area close to houses was completely extinguished by the firefighters just after the fire had been noticed. Nevertheless the fire attracted great numbers of beetles which stayed on the clear area for three days. As usual, beetle numbers declined over three days and on the fourth day all beetles had disappeared, most probably already searching for new fires.

Observations on larger burnt areas outside inhabited areas often yielded the result that beetles aggregate around larger hot spots. If a large hot spot (e.g. a fallen tree) was burning or glowing for more than three days, beetles usually could be found around it.

\section{DISCUSSION}

\section{THE FRESHLY BURNT AREA AS A VALUABLE ECOLOGICAL NICHE}

Although not evident at first glance, a freshly burnt area can be regarded as an interesting ecological niche for a wood-boring insect like $M$. atrata. If equipped with the appropriate sensory systems to prevent injuries by flames and hot surfaces, smoke and heat offer a good shelter against predators. As long as the burnt area is "active" (i.e. characterised by smoking hot spots), mating, foraging and oviposition can take place safely. As the burnt area cools down we have frequently observed that birds such as Australian Magpies (Cracticus tibicen) start to prey on M. atrata. As long as there is heat and smoke, however, birds stay away from those locations. This may be the reason that $M$. atrata gathers around hot spots.

The second and obviously most important reason is that the wood of the burnt trees is an ideal source of food for the wood-boring larvae. Especially closer to the ground the cambium layer has been killed by the intense heat preventing any further protective mechanisms like increased cell divisions around the tiny first larvae in order to squash the unwelcome intruder. Additionally, as already proposed by Poulton (1915), harmful volatile protective substances have been evaporated by the heat. As a result, a freshly burnt area is a kind of "land of plenty" for a woodborer like M. atrata. However, in order to profit from all advantages (protection and larval 

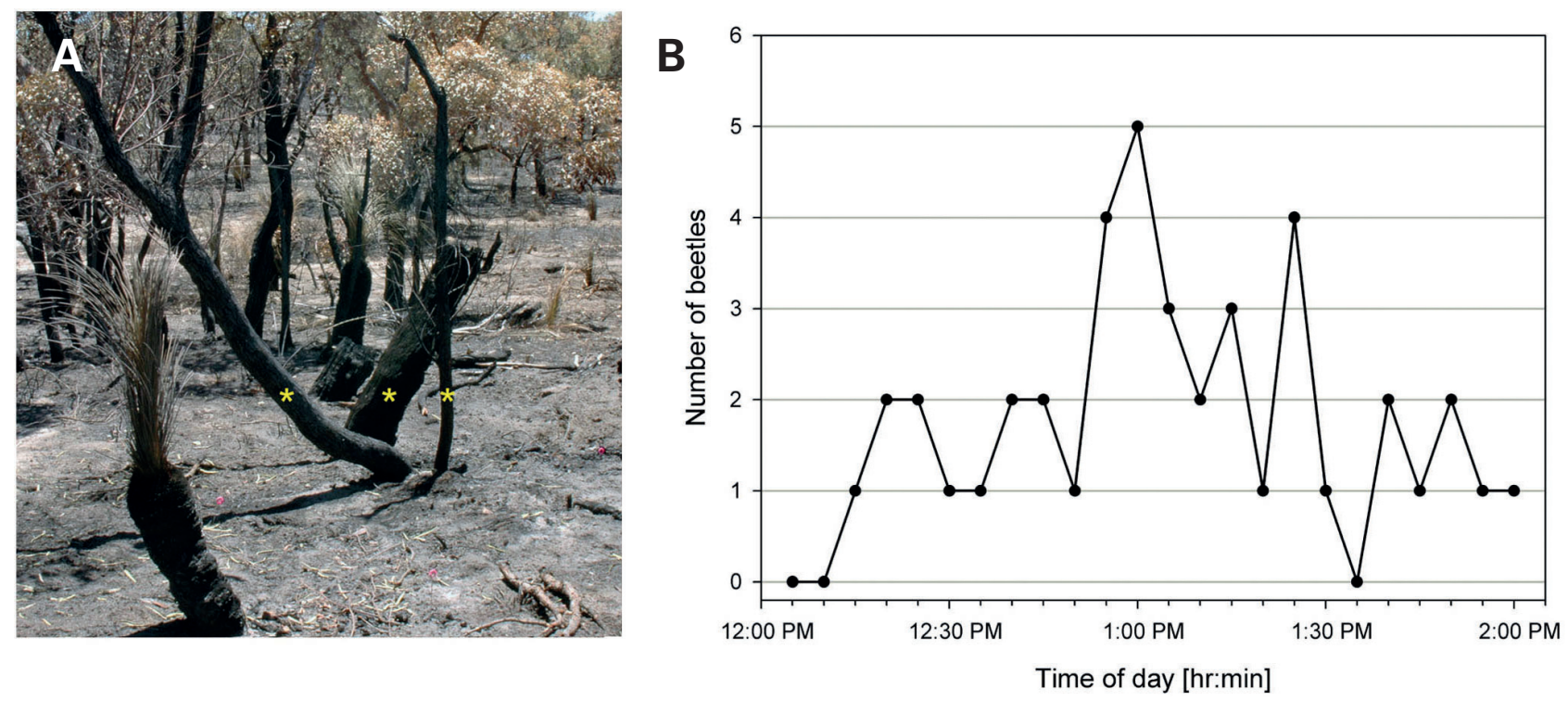

FIGURE 4 Beetle activity on an extinguished burnt area close to Farrington Road, North Lake, Western Australia (32 $04^{\prime} 52^{\prime \prime}$ S, $\left.115^{\circ} 50^{\prime} 49^{\prime \prime} \mathrm{E}\right)$ : A, small group of three burnt stems of different diameter (see asterisks) one day after a fire on 20 January 2013; no hot spots could be identified; B, Number of beetles visible from the viewpoint during two hours of observation; the decrease in beetle numbers during the first hour was caused by the setting up of the black canvas. Although erection of the canvas took only about 10 minutes it took one hour before the initial number of beetles observed before the disturbance (approximately 3 to 4 beetles) was reached.
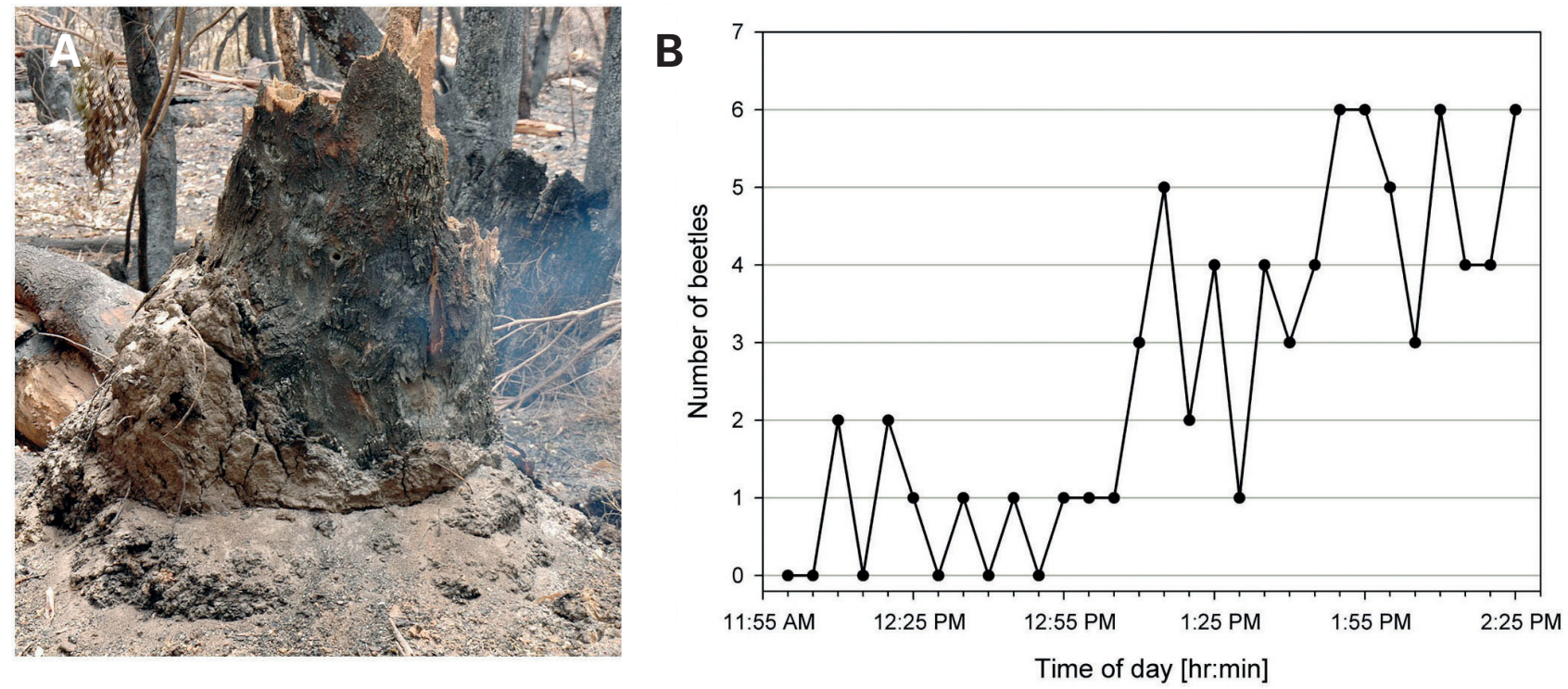

FIGURE 5 Beetle activity on a burnt area close to Reid / Roe Highway, Middle Swan, Western Australia at 3151'49"S, $116^{\circ} 00^{\prime} 56^{\prime \prime} \mathrm{E}: \mathrm{A}$, broken stump of a large eucalyptus tree; some smaller hot spots near the base of the stump still emitted smoke; $B$, number of beetles counted on the bark of the stump visible from the viewpoint three days after the fire on 16 January 2013. As in Figure 4 the decrease in numbers of beetles during the first hour was caused by setting up the canvas. Although erection took only about 10 minutes it took nearly one hour until the initial number observed before the disturbance (approximately 3 to 4 beetles) was reached. 

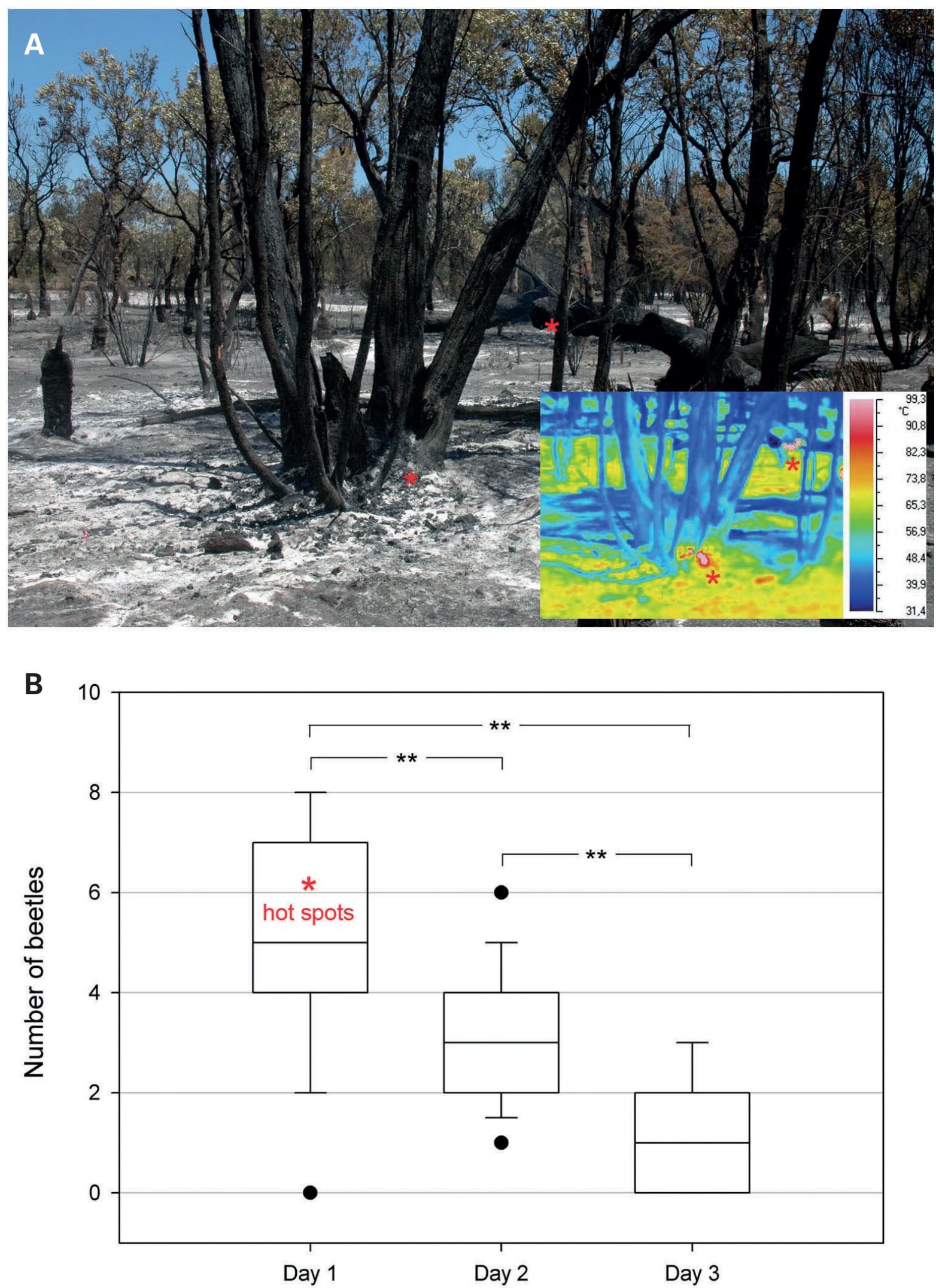

FIGURE 6 Progression of beetle activity on a single tree over a period of three days: A, eucalyptus tree with many basal side branches on a burnt area in the Gnangara-Moore River State Forest, Pinjar, Western Australia, near Higgins Road at $31^{\circ} 37^{\prime} 42^{\prime \prime}$ S, $115^{\circ} 52^{\prime} 07^{\prime \prime} E$. On day 1 after the fire two hot spots were still active (see red asterisks) and emitted some smoke. Inset shows IR image; B, number of beetles counted every five minutes over a period of two hours in the early afternoon on three consecutive days (21-23 January 2013). Symbol '**' indicates highly significant differences with a p-value set at $p<0.01$ (Friedman test). 
food still untouched by competitors), the burnt area has to be found as early as possible.

A further feature of a burnt area advantageous for a thermophilic beetle like $M$. atrata is the opening of the canopy caused by burning of the leaves and small branches so that the sunbeams can more readily reach the stems of the black tree trunks and the ground. Beetles can bask efficiently to quickly reach the high body temperatures necessary to become highly active. The sun-exposed burnt tree trunk, therefore, can be regarded as an ideal meeting place for males and females. This is in line with our observations that shaded trunks are clearly avoided. We also speculate that the smell of smoke may serve as a kind of pheromone substitute. This may be another reason that beetles are attracted to smouldering wood and gather around smoking hot spots. Beetles have been observed after sunset around street lights (Williams 1982; Hawkeswood 1992), which can most probably be interpreted as a misdirection by beetles which may have emerged on a nearby burnt area and have approached the bright streetlights as many other diurnal insects do during warm summer nights.

The value of a freshly burnt area as a favourable place to start reproduction is additionally demonstrated by the immediate arrival of other highly pyrophilous insects like the "Little Ash Beetle" Acanthocnemus nigricans (Hope, 1843) (Acanthocnemidae) and the flat bugs Aradus albicornis (Walker, 1873) and A. fuscicornis (Kormilev, 1966) (Aradidae) which all are also equipped with IR receptors (Champion 1922; Kreiss et al. 2005; Schmitz et al. 2010). However, these IR receptors are totally different from the abdominal receptors in $M$. atrata and, therefore, must have developed independently.
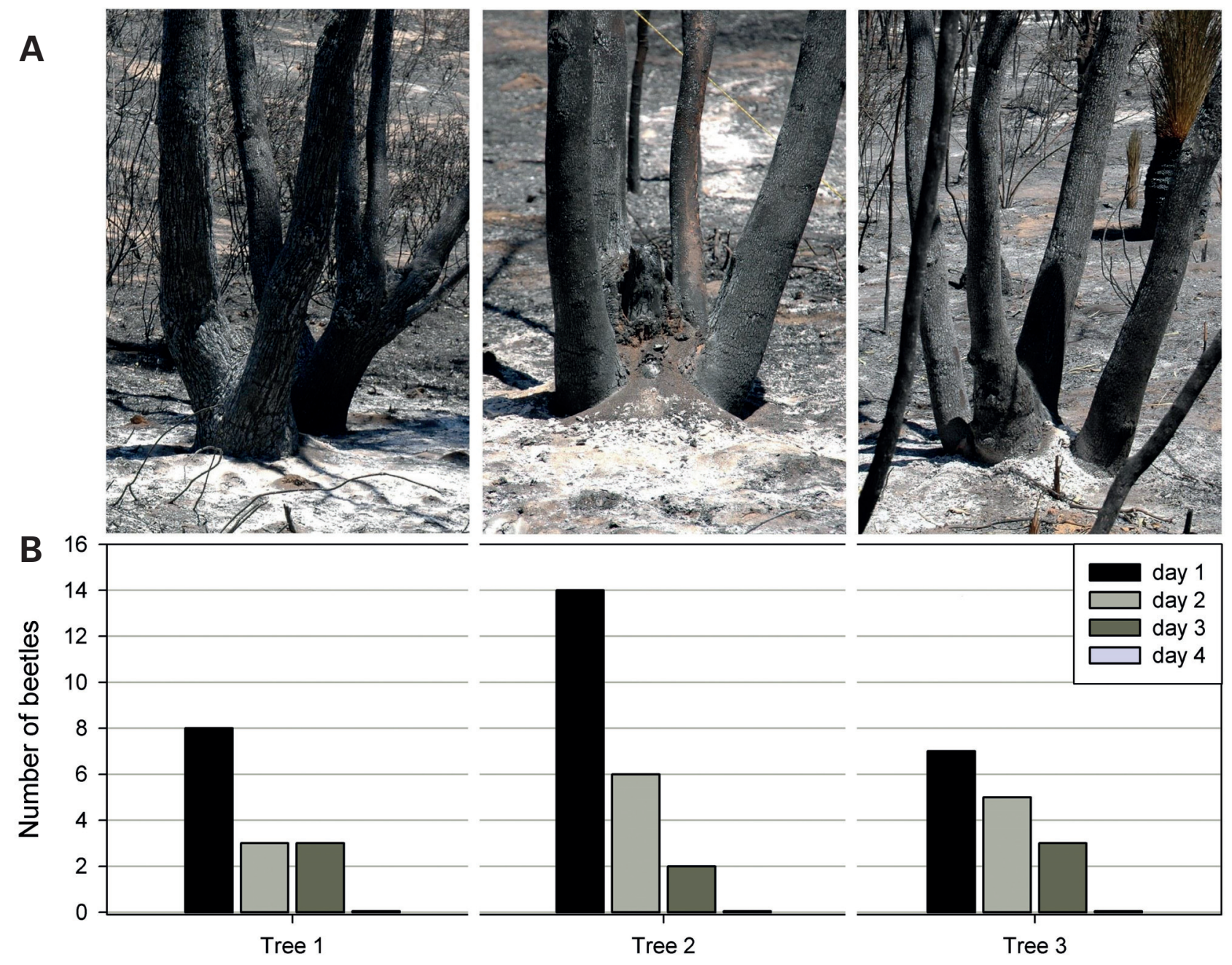

FIGURE 7 Progression of beetle activity over four days on three different trees (28-31 January 2013); observations started one day after the fire had been extinguished: $A$, pictures of the three trees. All trees were located on the same

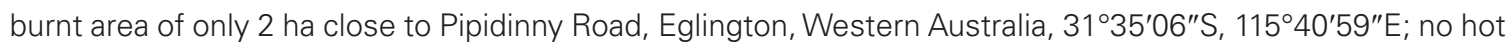
spots were active; $B$, beetles were always counted at 2:00 pm; on a given day beetle numbers did not differ significantly between trees (Friedman test; $p$-value $p<0.05$ ). 


\section{PREREQUISITES FOR EXPLOITING A BURNT AREA}

Even on a fire-prone continent like Australia that is characterised by frequent forest fires the outbreak of a fire in a given forest is unpredictable. Therefore it can be proposed that a strong evolutionary pressure has acted on sensors used by $M$. atrata to detect fires. While it is possible that receptors for visual, olfactory, acoustic, and thermal stimuli could be used, there is no information that M. atrata can hear a fire such as has been described, for example, in certain reed frogs of the West African savannah (Grafe et al. 2002). It is speculated that beetles performing a search flight could be able to see a huge smoke plume against the horizon. The view of a smoke plume may give the beetles their first hint that a bushfire is burning even if the wind does not blow the smoke into the direction of the beetle. Nevertheless, olfaction is certainly also very important for fire detection. It has been shown that $M$. atrata can smell several fire-specific compounds (Eßinger et al. 2010). An important group of marker volatiles are specific host plant terpenoids. Terpenes are released at low to moderate temperatures before ignition of the wood. It has been shown by electrophysiological experiments that $M$. atrata is able to smell $\alpha$ pinen and especially cineol, the main component of eucalyptus oil (Stefan Schütz, Göttingen, pers. communication). In the pre-combustion stage (at temperatures between $150-200^{\circ} \mathrm{C}$ ) thermal decomposition products of hemicellulose like furfural are emitted. If the wood finally burns (temperatures $200-250^{\circ} \mathrm{C}$ and above), guaiacol and its derivatives (e.g. 2-methoxyphenol) from the oxidation of lignin are emitted. All these key components can be detected by $M$. atrata with high sensitivity (Eßinger et al. 2010; Paczkowski et al. 2011).

So there is considerable evidence that $M$. atrata approaches a fire mainly guided by olfactory cues. Our observations demonstrate that $M$. atrata can only be found if at least a few burnt eucalyptus trees are available on the burnt area. This has been observed some years ago after a very small fire on a traffic island in Innaloo, a northern suburb of Perth. On this little island a few small eucalyptus trees were scorched by the fire and about a dozen $M$. atrata were found on the trees just after the fire has been extinguished. Small campfires made with eucalyptus twigs and leaves also attract $M$. atrata. In contrast, fires in pure Banksia woodlands or in pine plantations do not attract M. atrata at all. Thus a burnt area is only of interest for $M$. atrata if the typical eucalyptus specific smell (e.g. of cineol) can be perceived.

Particularly with regard to special receptors, fire adaptations are extensive in $M$. atrata. As a unique feature, M. atrata has developed IR receptors on the abdomen. A pair of circular IR receptors is situated on the second, third, and sometimes also on the fourth abdominal sternite (Schmitz et al. 2000, 2001; Mainz et al. 2004). A single IR receptor is located close to the lateral edge of the curved sternite and is characterised by a yellowish IR absorbing area (diameter of about 0.5 $\mathrm{mm}$ ) slightly sunken into the dark cuticle (Schmitz et al. 2001). In a flying beetle the organs are directed to the ground in an angle of roughly $45^{\circ}$. The receptor is innervated internally by a so-called sensory complex consisting of one large thermoreceptive neuron and a small chordotonal organ consisting of two mechanosensitive scolopidia (Schneider and Schmitz 2013). So far electrophysiological recordings have only been obtained from the thermoreceptive neuron. Results had shown that the neuron responds to an increase in temperature in a phasic-tonic way. Sensitivity, however, seems not to be high. A threshold of $400 \mathrm{~W} / \mathrm{m}^{2}$ has been determined (Schmitz and Trenner 2003). This rather low sensitivity does not point to a function of the IR receptors as detector for remote fires. Accordingly, beetles most probably make use of their IR receptors on a burnt area in order to prevent landing on a hot spot. We have never observed beetles running over glowing surfaces as reported by Poulton (1915). Additionally, there is no indication that $M$. atrata can tolerate high temperatures beyond $46^{\circ} \mathrm{C}$. Therefore, the IR receptors are used as an early warning system enabling the beetle to detect a hot spot before it becomes injured by a hot surface. However, the mechanosensitive chordotonal organ eventually could extend the measuring range thereby increasing the sensitivity of the organ which may allow detection of fires from greater distances (Schneider and Schmitz 2013).

\section{ACKNOWLEDGEMENTS}

Mike Cantelo and Brian Inglis from the Swan Coastal District Office of the Department of Parks and Wildlife (DPaW), Wanneroo, Western Australia, enabled us to visit bush fires and supported us during the last 13 years. Thanks also to all other people from DPaW in Wanneroo and Perth who helped us in all respects to conduct our field studies. The Wildlife Branch of DPaW (Perth) issued collecting and export permits. We are indebted to Mark S. Harvey (Western Australian Museum, Perth) for improving the English and to Horst Bleckmann (Institute of Zoology, Bonn University) for his continuous interest in our work. This study was supported by a grant from the German Science Foundation (DFG) to H.S.

\section{REFERENCES}

Champion, G.C. (1922). The geographical distribution and synonymy of the dasytid-beetle Acanthocnemus nigricans HOPE (=ciliatus PERRIS). Entomologist's Monthly Magazine 58: 77-79.

Eßinger, T.M., Becker, B., Sauerwald, T., Paczkowski, S., Schütz, S. and Kohl, D. (2010). Volatile gas sensors for large-scale drying of wood. Sensoren und Messsysteme 2010. Nürnberg, Germany.

Evans, H.F., Moraal, L.G. and Pajares, J.A. (2007). Biology, ecology and economic importance of Buprestidae and Cerambycidae. In: Lieutier, F., Day, K.R., Battisti, A., 
Grégoire, J.-C. and Evans, H.F. (eds.), Bark and Wood Boring Insects in Living Trees in Europe, A Synthesis. Springer-Verlag, Dordrecht, pp. 447-474.

Grafe, T.U., Dobler, S. and Linsenmair, K.E. (2002). Frogs flee from the sound of fire. Proceedings of the Royal Society of London Series B-Biological Sciences 269: 999-1003.

Hawkeswood, T.J. (1992). A list and notes on some nocturnally active beetles (Coleoptera) attracted to street lights at Townsville, north-eastern Queensland, Australia. Giornale Italiano di Entomologia 6: 5-8.

Hawkeswood, T.J. (2007). Review of the biology of the genus Merimna Saunders, 1868 (Coleoptera: Buprestidae). Calodema 9: 12-13.

Hawkeswood, T.J. and Peterson, M. (1982). A review of the larval host records for Australian jewel beetles (Coleoptera: Buprestidae). Victorian Naturalist 99: 240-251.

Kitchin, D.R. (2009). Notes on the biology of Merimna atrata (Gory \& Laporte) (Coleoptera: Buprestidae). Australian Entomologist 36: 1-2.

Kreiss, E.J., Schmitz, A. and Schmitz, H. (2005). Morphology of the prothoracic discs and associated sensilla of Acanthocnemus nigricans (Coleoptera, Acanthocnemidae). Arthropod Structure \& Development 34: 419-428.

Mainz, T., Schmitz, A. and Schmitz, H. (2004). Variation in number and differentiation of the abdominal infrared receptors in the Australian 'fire-beetle' Merimna atrata (Coleoptera, Buprestidae). Arthropod Structure \& Development 33: 419-430.

Moore, B.P. and Brown, W.V. (1985). The Buprestins: bitter principles of jewel beetles (Coleoptera: Buprestidae). Journal of the Australian Entomological Society 24: 81-85.

Paczkowski, S., Sauerwald, T., Weiß, A., Bauer, M., Kohl, D. and Schütz, S. (2011) Biomimetic gas sensors for largescale drying of wood particles, In: SPIE Smart Structures and Materials + Nondestructive Evaluation and Health Monitoring. International Society for Optics and Photonics, pp. $797505-8$.

Poulton, E.B. (1915). The habits of the Australian buprestid "fire-beetle" Merimna atrata, Lap. et Gory. Transactions of the Entomological Society of London, pt. 1, proc., iii-iv.
Schmitz, A., Schätzel, H. and Schmitz, H. (2010). Distribution and functional morphology of photomechanic infrared sensilla in flat bugs of the genus Aradus (Heteroptera, Aradidae). Arthropod Structure \& Development 39: 17-25.

Schmitz, H. and Schmitz, A. (2002). Australian fire-beetles. Landscope Spring 2002: 36-41.

Schmitz, H., Schmitz, A. and Bleckmann, H. (2000). A new type of infrared organ in the Australian "firebeetle" Merimna atrata (Coleoptera, Buprestidae). Naturwissenschaften 87: 542-545.

Schmitz, H., Schmitz, A. and Bleckmann, H. (2001). Morphology of a thermosensitive multipolar neuron in the infrared organ of Merimna atrata (Coleoptera, Buprestidae). Arthropod Structure \& Development 30: 99-111.

Schmitz, H. and Trenner, S. (2003). Electrophysiological characterization of the multipolar thermoreceptors in the 'fire-beetle' Merimna atrata and comparison with the infared sensilla of Melanophila acuminata (both Coleoptera, Buprestidae). Journal of Comparative Physiology A 189: 715-722.

Schneider, E.S. and Schmitz, H. (2013). Bimodal innervation of the infrared organ of Merimna atrata (Coleoptera, Buprestidae) by thermo- and mechanosensory units. Arthropod Structure \& Development 42: 135-142.

Tepper, J.G.O. (1887). Common native insects of South Australia. A popular guide to South Australian entomology. Part 1. Coleoptera or Beetles. E.S. Wigg\&Son, Adelaide, pp. $1-46$.

Williams, G.A. (1982). A note on Buprestidae (Coleoptera) observed at lights. Australian Entomological Magazine 8: 81.

Williams, G.A. and Williams, T. (1983). A list of the Buprestidae (Coleoptera) of the Sydney Basin, New South Wales, with adult food plant records and biological notes on food plant associations. Australian Entomological Magazine 9: 81-93.

MANUSCRIPT RECEIVED 4 SEPTEMBER 2014; ACCEPTED 11 DECEMBER 2014. 